\title{
BMJ Open Translation and validation of the Cancer-Related Fatigue Scale in Greek in a sample of patients with advanced prostate cancer
}

\author{
Andreas Charalambous, ${ }^{1,2}$ Charis Kaite, ${ }^{1}$ Marianna Constantinou, ${ }^{1}$ \\ Christiana Kouta ${ }^{1}$
}

To cite: Charalambous A, Kaite C, Constantinou M, et al. Translation and validation of the CancerRelated Fatigue Scale in Greek in a sample of patients with advanced prostate cancer. BMJ Open 2016;6: e011798. doi:10.1136/ bmjopen-2016-011798

- Prepublication history for this paper is available online. To view these files please visit the journal online (http://dx.doi.org/10.1136/ bmjopen-2016-011798).

Received 7 March 2016 Revised 30 September 2016 Accepted 3 October 2016

CrossMark

${ }^{1}$ Department of Nursing, School of Health Sciences, Limassol, Cyprus

${ }^{2}$ Department of Nursing, University of Turku, Turku, Finland

\section{Correspondence to} Dr Andreas Charalambous; andreas.charalambous@cut. ac.cy

\section{ABSTRACT}

Objective: To translate and validate the CancerRelated Fatigue (CRF) Scale in the Greek language. Design: A cross-sectional descriptive design was used in order to translate and validate the CRF Scale in Greek. Factor analyses were performed to understand the psychometric properties of the scale and to establish construct, criterion and convergent validity. Setting: Outpatients' oncology clinics of two public hospitals in Cyprus.

Participants: 148 patients with advanced prostate cancer undergoing chemotherapy.

Results: The Cancer Fatigue Scale (CFS) had good stability (test-retest reliability $r=0.79, p<0.001$ ) and good internal consistency (Cronbach's $\alpha$ coefficient for all 15 items $\alpha=0.916$ ). Furthermore, the Kaiser-MeyerOlkin Measure of Sampling Adequacy (KMO value) was found to be 0.743 and considered to be satisfactory $(>0.5)$. The correlations between the CFS physical scale (CFS-FS scale) and the European Organization for Research and Treatment of Cancer (EORTC) QLQ-C30 physical subscales were found to be significant $(r=-0.715)$. The same occurred between CFS cognitive and EORTC cognitive subscale $(r=-0.579)$. Overall, the criterion validity was verified. The same occurs for the convergent validity of the CFS since all correlations with the Global Health Status (q29-q30) were found to be significant.

Conclusions: This is the first validation study of the CRF Scale in Greek and warrant of its use in the assessment of prostate cancer patient's related fatigue. However, further testing and validation is needed in the early stages of the disease and in patients in later chemotherapy cycles.

\section{INTRODUCTION}

A widely used definition of cancer-related fatigue (CRF), is the one proposed by the National Comprehensive Cancer Networks definition (NCCN): 'CRF is a distressing persistent, subjective sense of physical, emotional and/or cognitive tiredness related to

\section{Strengths and limitations of the study}

- The current study adapted and validated the Cancer Fatigue Scale (CFS) in a site-specific cancer population (patients with advanced prostate cancer) through a rigorous methodological approach.

- The aforementioned scale was validated through factor analysis in order to describe its psychometric properties.

- The study provided information on the validity of the CSF scale on outpatients. Further validation is needed for inpatients with similar clinical characteristics.

- A stratified sampling method would allow the consideration of important factors such as the stage of the disease (ie, earlier stages) and chemotherapy cycles (ie, patients in later chemotherapy cycles).

cancer or cancer treatment that is not proportional to recent activity and interferes with usual functioning, ${ }^{1}$, (FT1). A different conceptual perspective was proposed by Cella $e t a l^{2}$ who stated that: "Fatigue is a subjective state of overwhelming and sustained exhaustion and decreased capacity for physical and mental work that is not revealed by rest" (ref. 2, p. 369).

In the first definition, fatigue is described as a subjective sense and in the second, it is described as a subjective state. Subjective means that it is totally to the patient's discretion to feel it or express it, which could lead us to the use of self-reported measures. Therefore, sense means that the patient has this feeling and state means that the patient is at that particular condition in that specific time.

In relation to assessment, the definition of Cella $e t a l^{2}$ provides the different ways by which fatigue is distinct from normal 
tiredness, including its severity and chronicity and at the same time underlines that it cannot be affected by actions that typically provide relief from tiredness, as well as emphasising its clinical significance and its multidimensional qualities. ${ }^{3}$

As far as the definition of $\mathrm{NCCN}^{2}{ }^{2}$ this does not include the severity of the symptom as well as its continuity, since fatigue can continue to affect the patient following the completion of the cancer treatment during the survivorship phases. ${ }^{45}$

The prevalence of CRF, ranges from $59 \%$ to $100 \%$ according to the clinical status of cancer. ${ }^{5}$ CRF occurs during and after treatment in $70-80 \%$ of patients in the clinical trial setting and is distinct to the type of cancer, treatments and method of assessment. ${ }^{6}$ Although patients with prostate cancer tend to report lower severe fatigue levels compared with other patients (ie, patients with breast cancer), ${ }^{7}$ they were most likely to report fatigue of more than 6 months' duration. ${ }^{8}$ Furthermore, patients with prostate cancer tend to report higher levels and more severe fatigue as the disease progressed. ${ }^{6}$ This results in a considerable impact on a patient's ability to function over time (physical and cognitive); hence, this symptom is among the most distressing all of those reported by patients. The prevalence of fatigue and the factors that predict interindividual differences in trajectories of fatigue among patients with prostate cancer can differ when compared with patients with other types of cancer. ${ }^{9}$ For example, patients with prostate cancer on androgen deprivation therapy (ADT) can experience ADT-induced fatigue. This fatigue is a complex multidimensional entity with multifactorial and complex pathophysiology that shares many overlapping features with other ADT-related toxicities such as depression, low mood and reduced libido. ${ }^{10}$

International literature supports that there is a multidimensionality to fatigue that called for different scales as an effort to capture the different dimensions of fatigue as best as possible. ${ }^{3}$ As a result, the use of different measuring tools created a difficulty to compare the findings of the different studies. ${ }^{3}$

The assessment of CRF can include varying methods including: (1) unidimensional scales and (2) multidimensional scales. ${ }^{3} 4{ }^{11}$ Unidimensional scales tend to assess only one dimension of fatigue (ie, the physical), whereas multidimensional scales assess two to five different aspects of fatigue (ie, behavioural, cognitive, somatic and affective). ${ }^{11}$ Unidimensional scales employ a single item for assessing fatigue as part of a symptom checklist. Those include but are not limited to: (1) the Symptoms Distress Scale or McClorke and Young's Symptom Distress Scale $^{12}$ and (2) the Rotterdam's Symptoms Checklist. ${ }^{13}$

The Symptoms Distress Scale assesses cancer-related symptoms in which patients have to respond about how they have been feeling during the preceding week. The scale consists of 13 items corresponding to different symptoms, assessing the patient's response on a 5-point Likert scale (5 indicates the most distress). This scale has been mainly used in patients with lung cancer. ${ }^{14} 15$
Other symptoms include: (1) nausea, (2) mood, (3) appetite, (4) insomnia, (5) pain, (6) bowel patterns, (7) concentration and (8) appearance. The above can be summed to provide total symptom distress ranging from 13 to 65 with greater levels of symptoms distress indicated by higher scores. ${ }^{16}$ The reliability of the Symptom Distress Scale was found to be 0.82 when assessed on 53 patients with chronic illness, ${ }^{16}$ whereas the validity of the scale had been established by the identification of concerns of 86 patients receiving chemotherapy or radiation therapy. ${ }^{17}$

The Rotterdam's Symptoms Checklist ${ }^{13}$ was first used to assess the psychological and physical distress of patients with cancer in three studies. The first study was conducted on 95 female patients with cancer of an outpatient clinic for chemotherapy or follow-up. The second study was a randomised controlled trial comparing two types of chemotherapy in 56 women with ovarian cancer. The third study compared the quality of life in different types of patients with cancer with that of a group of 'normal' controls $(n=609)$. The Rotterdam's Symptoms Checklist was found to be reliable with a Cronbach's $\alpha$ ranging from 0.88 to 0.94 .

A modified version of the Rotterdam Symptoms Checklist was also found to be reliable $(\alpha=0.88)$ and valid (convergent validity) in a group of 1005 male and female patients with cancer. The tool was highly correlated to the Medical Outcomes Study 36-Item Short-Form Health Survey, physical functioning scale (MOS-SF-36 PF scale) $(\mathrm{r}=-0.59)$ and the Medical Outcomes Study 36-Item Short-From Health Survey, General Health scale (MOS SF-36 GH scale) $(\mathrm{r}=-0.61)$. Weaker correlations were found in relation to the Mood and Physical Symptoms Scale $(r=-0.21)$ and the Functional Assessment of Chronic Illness Therapy Spiritual Well-Being $(\mathrm{r}=0.31)$.

The other widely used scale is the European Organization for Research and Treatment of Cancer (EORTC) Quality of Life Questionnaire Core 30 (QLQC30) quality of life measure. ${ }^{18}$ The EORTC QLQ-C30 consists of 30 items regarding the quality of life. It has been used in two studies, ${ }^{19} 20$ in a population exceeding 2000 patients in each study where the tool demonstrated good psychometric properties. However, in the study of Knobel et al, ${ }^{19}$ the EORTC QLQ-C30 was found to have a ceiling effect in patients with advanced cancer and is therefore not recommended to be used solely for this group. Nevertheless, an advantage of the scale is its ability to show fatigue data in studies when the full instrument is used. ${ }^{11}$ In addition, the scale was not designed to measure explicitly CRF. The EORTC QLQ-C30 has been validated in Greek. ${ }^{21}$

The Medical Outcomes Study 36-Item Short-Form Health Survey $\left(\right.$ SF-36) ${ }^{22}$ includes a fatigue subscale consisting of four items measuring the frequency of fatigue during the preceding 4 weeks. Although it is considered to be useful for measuring a general health status, it is neither limited nor explicitly designed to measure CRF. The SF- $36^{22}$ has been validated in Greek. ${ }^{23}$ The 
MDAnderson Symptom Inventory (MDASI) assesses the severity of 13 common (core) cancer-related symptoms: pain, fatigue (tiredness), nausea, disturbed sleep, being distressed, shortness of breath, difficulty remembering, lack of appetite, feeling drowsy, dry mouth, feeling sad, vomiting and numbness or tingling. ${ }^{24}$ Fatigue is assessed by a single item that measures the severity of fatigue in the previous 24 hours. The inventory was found to have an internal consistency of $\alpha=0.85-0.87$ and it was validated to measure CRF although it is only limited to the severity of the assessment. ${ }^{23}$ The MDASI has been validated in Greek. ${ }^{25}$

In addition, the Zung Self-Rating Depression Scale ${ }^{26}$ encompasses a single fatigue item that is assessed on a 4-point Likert Scale (none, some of the time, most of the time, all of the time), during the preceding week. Although the scale was found to be a simple screening tool, it has not been developed for CRF and cannot measure CRF severity. ${ }^{4}$

There are also independent single-item tools that focus on the assessment of fatigue, such as the Rhoten Fatigue Scale. ${ }^{27}$ This is a single-item $0-10$ point graphic rating scale that measures the fatigue severity in the present. This scale is simple and easy to use, regardless of its limitation to severity assessment and not being developed to measure CRF explicitly. ${ }^{4}$ In addition, the Visual Analogue Fatigue Scale $^{28}$ is a $10 \mathrm{~cm}$ visual analogue scale designed to measure fatigue severity from 'I do not feel tired' to 'I feel totally exhausted' and is considered to be simple and easy to use, even on healthy individuals. However, it is limited to severity assessment and is considered to be inappropriate for many types of statistical evaluation. ${ }^{4}$

The Brief Fatigue Inventory (BFI $)^{29}$ is a 9-items numerical scale, which was originally validated in 305 patients with various types of cancer. Its internal consistency was found to be $\alpha=0.96$ and its convergent validity against Profile of Moods States Fatigue subscale (POMS-F) was found to be $r=0.84$. The BFIs cut-off scores to differentiate between mild, medium and severe fatigue, had not been validated and are considered to be used solely for screening purposes. ${ }^{4}$ The BFI has been validated in Greek. ${ }^{30}$

The Functional Assessment of Cancer Therapy Fatigue (FACT-F) subscale ${ }^{31}$ is a 13-item scale, mainly used in interventional studies. Its validation was made in a sample of 50 patients with cancer with various cancer diagnoses. Its internal consistency was found to be $\alpha=0.95$ for physical functioning and the test-retest reliability as $\mathrm{r}=0.90 .^{32}$

Finally, the POMS- $\mathrm{F}^{33}$ was primarily used as a measure of workforce health. POMS-F consists of seven items and was used in a 695 mixed work population and psychiatric patients. Its internal consistency was found to be $\alpha=0.90$ 0.94 in relation to physical functioning and the test-retest reliability showed $\mathrm{r}=0.66$. The POMS-F has been used in non-cancer population ${ }^{34}$ and in cancer population. ${ }^{35}$

Literature shows that there is a wide range of multidimensional scales for assessing fatigue such as the: (1) Lee
Fatigue Scale (LFS), ${ }^{36}$ (2) FACT-F, ${ }^{31}$ (3) Multidimensional Fatigue Symptom Inventory, ${ }^{37}$ (4) Fatigue Assessment Questionnaire, ${ }^{38}$ (5) Revised Paper Fatigue Scale (PFS-R), ${ }^{39}$ (6) Revised Shwartz Cancer Fatigue Scale, ${ }^{40}$ (7) Cancer Fatigue Scale (CFS), ${ }^{41}$ (8) Fatigue Symptom Inventory $^{42}{ }^{43}$ and (9) the Chalder Fatigue Scale. ${ }^{44}$

These multidimensional scales are not without limitations. The $\mathrm{LFS}^{36}$ has not been designed for patients with cancer and the PFS-R, ${ }^{39}$ which even though used in a number of studies with patients with breast cancer undergoing chemotherapy, ${ }^{41-46}$ it could only be used in patients currently experiencing fatigue and has limited applicability to other cancer types. ${ }^{45-50}$

Thus, the scope of the current study is a twofold one. First, to translate and validate the multidimensional CFS in Greek and second to validate the scale in a specific group of patients, explicitly those diagnosed with prostate cancer. This is a major contribution to the relevant literature as the original study as well as the subsequent validations studies did not test the CFS in this specific population.

\section{METHODS}

\section{Design, sample population}

This was a cross-sectional descriptive study performed at the Outpatients Oncology Clinics of two public hospitals in Cyprus that receive the highest numbers of outpatient visits per year. These were purposively chosen in order to provide a better generalisability to the sample, as patients come from all geographical regions.

The current study, regardless of its many similarities with preceding validation studies, is not following the exact methods of the original study ${ }^{41}$ or the subsequent ones. $^{51-53}$

The study included patients with advanced prostate cancer, under hormonal therapy with no response, as well as on chemotherapy treatment primarily with docetaxel or combination chemotherapy. The patients were recruited during the follow-up visit following the completion of the third cycle of treatment where they completed the CFS. In order to assess the test-retest reliability of the scale, a repeated measure was completed by the patients with an interval of 8 days. The target for the test-retest analysis was at least $50 \%$ of all participants. Non-Greek speaking patients, and patients with a score $<50$ on the Karnofsky Performance Scale Index or a mean of $<50$ on the Attentional Function Index (AFI) were excluded from the study. The Karnofsky Performance Scale index score was set to 50 to ensure that patients taking part in the study did not have a significant functional impairment that would not allow them to independently and accurately complete the assessment scale. The AFI score was set to 50, to ensure that patients did not have severe cognitive alterations on their daily functioning, as these were imposed by cancer, treatment or fatigue. Such alterations could negatively impact on the patients' ability to successfully 
complete the assessments. Additional exclusion criteria included patients: (1) receiving or planned to receive conventional or complementary treatment for fatigue or (2) with an impaired cognitive ability or (3) that were referred to palliative care services for end-of-life care.

Prior to the study, the participants received written information on the aims and objectives of the study. A written consent was obtained by every participant. The study is in line with the principles described by the Helsinki Declaration. ${ }^{54}$

\section{Assessment scale}

The $\mathrm{CFS}^{41}$ consists of 15 -items that assess fatigue in relation to physical, affective and cognitive dimensions in the present moment. Each item is assessed on a 5-point Likert scale. Its internal consistency was found to be $\alpha=0.79-0.89 .{ }^{41}$ It is also considered to be simple and easy to complete and applicable to patients currently experiencing fatigue. The validity and reliability of the scale has been tested in German, Chinese and Arabic. ${ }^{51-53}$

The German validation study of Kröz et $a \bar{l}^{1}$ on a sample of 114 patients with cancer, illustrated that the scale demonstrated a strong construct and content validity. Reliability results showed: Cronbach's a: $r=0.94$, retest reliability: $r r t=0.82$. The convergence criteria correlate was found to be between $\mathrm{r}=0.44$ and $\mathrm{r}=0.65$ (all $\mathrm{p}<0.001$ ).

The Iranian validation study ${ }^{52}$ was conducted on a sample of 112 patients with breast cancer visiting the Iranian Centre for Breast Cancer for their treatment or follow-up. It was found to be a reliable tool (total scale $\alpha=0.94$ ) but also across all subscales namely physical, affective, cognitive with Cronbach's $\alpha$ coefficients 0.92, $0.89,0.85$, respectively. Furthermore, known groups comparison analysis was used, which revealed satisfactory results in relation to the Iranian version of the scale's validity. The questionnaire discriminated well between subgroups of patients differing in clinical status, as defined by disease stage. Therefore, significant correlations were found $(\mathrm{r}=0.61,0.58,0.60$ and 0.62 for physical, affective, cognitive and total fatigue, $\mathrm{p}<0.01$ ).

A validation study was conducted in Taiwan by Shun et $a \tilde{l}^{3}$ in a convenience sample of 243 patients with cancer visiting an outpatient chemotherapy centre. The results showed that the SDs and means ranged from 0 to 60 and the Cronbach $\alpha$ was found to have increased from 0.83 to 0.85 after deleting item 14 (Can you encourage yourself to do anything?). The internal consistency coefficient $\alpha$ 's were found to be as follows: (1) physical domain $(\alpha=0.87)$, (2) affective domain $(\alpha=0.61)$ and (3) cognitive domain $(\alpha=0.62)$. Furthermore, a principal axis factoring analysis revealed that $43.12 \%$ of the common variance was explained by the three factors.

The Greek version of the scale was translated from the English version of the scale through a 5-phase approach according to the guidelines of Beaton et al. ${ }^{55}$ First, two bilingual translators translated it in Greek. Then, the synthesis of the two translations occurred where a common consensus translation was produced. After that, the scale was blindly back translated to the original language by two translators. A consensus version was produced by an experts committee in line with the semantic, idiomatic, experiential and conceptual equivalence. The experts committee consisted of seven health professionals, two language professionals and four translators involved in the process. The questionnaire was pretested in a convenience sample of 15 patients with prostate cancer who were asked to provide their perspective and understanding of each of the 15 items included in the instrument.

\section{Analysis}

IBM SPSS, V.19.0 (IBM Corp. IBM SPSS Statistics for Windows, Version 19.0. Armonk, New York, USA: IBM Corp, 2010) was used to perform statistical analyses. The test-retest reliability of the total and subscale scores CFS were evaluated using Pearson correlation coefficients by comparing the scores at the test and retest phases. For the Pearson correlation coefficient, reliability was defined acceptable $(>0.7)$, good $(>0.8)$ and excellent (>0.9).$^{56}$ Pearson correlation coefficients were computed between the CFS total/subscale scores and the EORTC QLQ-C30 fatigue subscale, as well as between the subscales of CFS and the corresponding EORTC QLQ-C30 functional scales (physical, cognitive). Furthermore, a simple and multiple regression analysis was performed in order to examine the effect that CRF has on the Quality of Life (QoL) of patients with advanced prostate cancer. As a dependent variable, global health status (QoL) was used in all models and as independent variables, the total CRF (CFS) and the subscales of CFS, alone or independently. The construct validity of the survey was evaluated using a factor analysis with a Varimax rotation.

\section{RESULTS}

\section{Participant characteristics}

A total of 148 men, diagnosed with advanced prostate cancer completed the CFS (test) and 119 patients completed the assessment for a second-time retest (response rate $68.5 \%$ and $80 \%$, respectively). The majority of patients $(68.2 \%)$, were living in Paphos, were aged between 61 and 70 years $(31.8 \%)$ and their time of diagnosis was 6 months to 3 years $(59.5 \%)$. Their level of education was mainly secondary $(28.4 \%)$, while $28.4 \%$ were of higher education (college/polytechnic) or had a university degree, respectively. Furthermore, as far as their supporting system, family and cancer associations were found to be their referred supporting system $(89.9 \%)$ (table 1$)$.

\section{Analysis of reliability}

Descriptive data on the three subscales of the CFS: total before (test) and after (retest) are reported in table 2. In all cases, CFS scores decreased slightly between the test and retest scores, reflecting a slight decrease in fatigue impact. 
Table 1 Participant characteristics $(\mathrm{N}=148)$

\begin{tabular}{lrr}
\hline Variable & N & Per cent \\
\hline Area of residence & & \\
Nicosia & 34 & 23.0 \\
Limassol & 7 & 4.7 \\
Paphos & 101 & 68.2 \\
Larnaca & 6 & 4.1 \\
Age & & \\
40-50 & 25 & 16.9 \\
51-60 & 37 & 25.0 \\
61-70 & 47 & 31.8 \\
>70 & 39 & 26.4 \\
Time from diagnosis & & \\
6 months-3 years & 88 & 59.5 \\
4-6 years & 45 & 30.4 \\
7-10 years & 6 & 4.1 \\
>10 years & 9 & 6.1 \\
Level of education & & \\
No formal education & 27 & 18.2 \\
Primary school & 37 & 25.0 \\
Secondary school & 42 & 28.4 \\
Higher education (college/polytechnic) & 21 & 14.2 \\
University degree & 21 & 14.2 \\
Supporting system & & \\
Family (spouse, children) & 10 & 6.8 \\
Cancer patient association & 5 & 3.4 \\
Family and cancer patient association & 133 & 89.9 \\
\hline & & \\
\hline
\end{tabular}

The test-retest correlation coefficients of each factor and the total score between the test and retest phases were found above the acceptable $0.7(p<0.001)$.

The item-to-item correlations were found to be: minimum $=0.5$, maximum $=0.52$ and the Cronbach's $\alpha$ was $\alpha=0.916$, which indicated high internal consistency. ${ }^{57}$ Table 2 shows that the reliability/internal consistency of the total fatigue scale and the three subscales were found to be very satisfactory, with Cronbach's $\alpha$ close to 1 for all scales (table 3).

\section{Construct validity}

The construct validity of the survey was evaluated using a factor analysis with a Varimax rotation. The fit of the model was examined through the assumptions of factor analysis. Thus, the Kaiser-Mayer-Olkin (KMO) value was found to be 0.743 and considered to be satisfactory $(>0.5) .{ }^{57} \mathrm{KMO}$ is a Measure of Sampling Adequacy overall and for each variable. ${ }^{58-60}$ In other words, it constitutes a summary of how small the partial correlations are relative to the original (zero-order) correlations. $\mathrm{KMO}$ variables $>0.8$ can be considered good (the component or factor analysis will be useful for these variables). It usually occurs when most of the zero-order correlations are positive. In addition, KMO values $<0.5$ occur when most of the zero-order correlations are negative. A value of 0.6 is a suggested minimum.

In addition, Bartlett's test of sphericity revealed that the original correlation matrix is not an identity matrix where there are significant correlations between the variables (ie, the 15 items of the scale). In particular, Bartlett's test of sphericity gave a $X^{2}=2232.429$ with a $\mathrm{p}$ value $<0.001$. Bartlett's test of sphericity ${ }^{61}$ tests the null hypothesis that the correlation matrix constitutes an identity matrix. An identity matrix is in which all diagonal elements are 1 and all diagonal elements are 0 . In combination, KMO and Bartlett's test of sphericity can provide a minimum standard, which should be passed before a factor analysis is conducted.

The Greek version of CFS, extracted three components similar to the original fatigue scale. ${ }^{41}$ These components corresponded to the physical, affective and cognitive subscales that explained a total of $74.3 \%$ of the variance. Items 1, 2, 3,6,12, 15 loaded on the physical subscale, meaning that only item 9 of the original scale was not on the physical scale. Item 9 (Do you feel fed up?) had a higher loading on the cognitive scale in the Greek version and in physical subscale 0.412 , compared with 0.672 on the cognitive scale. The affective subscale was constructed exactly as the original version with items $5,8,11,14$. The same applied to the cognitive subscale where items $4,7,10,13$ were included in addition to item 9. This means that the three dimensions of the original fatigue scale appeared to also be present in the Greek version of the scale with a slight variation to one item (table 4).

\section{Criterion-related validity of CFS}

The CFS was tested for its correlation to the validated EORTC QLQ-C 30 fatigue scale and its physical and cognitive subscales. The EORTC QLQ-C 30 was chosen primarily because it adopts a framework that is informed by the assessments of the physical and cognitive functions of the patient as well as the assessment of fatigue. This

Table 2 Descriptive data and test-retest reliability: for the three subscales and total score of the Cancer Fatigue Scale (CFS) before and after

\begin{tabular}{|c|c|c|c|c|c|}
\hline \multirow{2}{*}{$\begin{array}{l}\text { CFS subscales and } \\
\text { total scale score }\end{array}$} & \multicolumn{2}{|c|}{ Before } & \multicolumn{2}{|l|}{ After } & \multirow{2}{*}{$\begin{array}{l}\text { Test-retest reliability } \\
\text { (correlation coefficient) }\end{array}$} \\
\hline & $\overline{\mathbf{M}}$ & SD & $\overline{\mathbf{M}}$ & SD & \\
\hline CFS physical & 14.21 & 8.3 & 13.93 & 7.9 & $0.80^{\star}$ \\
\hline CFS affective & 10.80 & 7.4 & 10.17 & 6.8 & $0.84^{\star}$ \\
\hline CFS cognitive & 8.92 & 11.0 & 7.98 & 10.7 & $0.75^{\star}$ \\
\hline CSF total & 29.63 & 21.2 & 27.39 & 20.6 & $0.79^{\star}$ \\
\hline
\end{tabular}

*Significant at $p<0.001$. 
Table 3 Item, subscale and scale descriptive and reliability measurements $(N=148)$

\begin{tabular}{lclll}
\hline Item & Mean (min-max) & SD & $\boldsymbol{\alpha}$ if item deleted & Item/scale correlation \\
\hline Total CFS & $26.77(5-52)$ & 12.05 & - & - \\
Physical subscale & $11.37(0-25)$ & 7.25 & - & - \\
Q1 & 1.51 & 1.204 & 0.907 & 0.700 \\
Q2 & 1.53 & 1.291 & 0.903 & 0.818 \\
Q3 & 1.80 & 1.318 & 0.905 & 0.762 \\
Q6 & 1.71 & 1.144 & 0.908 & 0.697 \\
Q9 & 1.83 & 1.248 & 0.910 & 0.629 \\
Q12 & 1.26 & 1.246 & 0.908 & 0.688 \\
Q15 & 1.72 & 1.293 & 0.904 & 0.799 \\
Affective subscale & $10.38(2-16)$ & 4.11 & - & - \\
Q5 & 2.97 & 1.100 & 0.908 & 0.686 \\
Q8 & 2.36 & 1.166 & 0.915 & 0.457 \\
Q11 & 2.59 & 1.081 & 0.915 & 0.448 \\
Q14 & 2.45 & 1.203 & 0.912 & 0.548 \\
Cognitive subscale & $5.02(0-14)$ & 3.51 & - & - \\
Q4 & 1.48 & 1.204 & 0.909 & 0.640 \\
Q7 & 1.09 & 1.096 & 0.916 & 0.434 \\
Q10 & 0.902 & 0.916 & 0.402 \\
Q13 & 1.31 & 1.243 & 0.914 & 0.521
\end{tabular}

framework is similar to that of CRF, which characterises fatigue in relation to physical, affective and cognitive elements. ${ }^{41}$ Furthermore, its validity and sensitivity has been previously assessed in a population of patients with advanced cancer. ${ }^{19}$ A Pearson correlation coefficient was performed between the CFS total/subscale scores and other fatigue instrument scores, that is, the EORTC QLQ-C 30 fatigue subscale, as well as between the subscales of CFS and the corresponding EORTC QLQ-C 30 functional scales. The scoring of all subscales was performed in line with the EORTC QLQ-C30 Scoring Manual $^{15}$ where the means of all the items in each subscale (raw scores) were transformed into scores from 0 to 100 .

As far as the criterion validity of the CFS, all correlations were found to be significant. However, the most important correlation found was between CFS and EORTC fatigue, which directly shows the criterion

Table 4 Factor analysis (followed by Varimax rotation) of the cancer fatigue scale $(\mathrm{N}=148)$

\begin{tabular}{lrrr}
\hline Item & Components & & \\
\hline 1. Do you become tired easily? & $\mathbf{1}$ & $\mathbf{2}$ & $\mathbf{3}$ \\
2. Do you have the urge to lie down? & 0.913 & 0.170 & 0.036 \\
3. Do you feel exhausted? & 0.777 & 0.303 & 0.303 \\
4. Do you feel you have become careless? & 0.873 & 0.145 & 0.230 \\
5. Do you feel energetic? & 0.495 & 0.063 & 0.604 \\
6. Does your body feel heavy and tired? & 0.426 & 0.803 & 0.101 \\
7. Do you feel that you more often make errors while speaking? & 0.618 & 0.198 & 0.420 \\
8. Do you feel interest in anything? & 0.066 & 0.071 & 0.817 \\
9. Do you feel fed-up? & 0.101 & 0.919 & 0.045 \\
10. Do you feel you have become forgetful? & 0.412 & 0.101 & 0.672 \\
11. Can you concentrate on certain things? & 0.367 & -0.303 & 0.652 \\
12. Do you feel reluctant? & 0.113 & 0.861 & 0.057 \\
13. Do you feel that your thinking has become slower? & 0.825 & 0.118 & 0.180 \\
14. Can you encourage yourself to do anything? & 0.111 & 0.184 & 0.822 \\
15. Do you feel such fatigue that you don't know what to do with yourself? & 0.222 & 0.890 & 0.066 \\
Eigenvalue & 0.730 & 0.272 & 0.366 \\
\% Variance explained & 7.012 & 2.698 & 1.435 \\
Eigenvalue after rotation & 46.745 & 17.986 & 9.568 \\
\% Variance explained after rotation & 4.615 & 3.436 & 3.094 \\
\hline${ }^{*}$ Eigenvalue: it is the variance in all the variables, which is accounted for by that factor. A factor's eigenvalue may be computed as the sum of \\
its squared factor loadings for all the variables. ${ }^{*}$ ?
\end{tabular}


validity of CFS, where the two fatigue scales are positively and significantly correlated. Additionally, the correlations between the CFS physical and EORTC physical subscales were found to be significant $(\mathrm{r}=-0.715)$. The same occurred between CFS cognitive and EORTC cognitive subscale $(\mathrm{r}=-0.579)$. As $\mathrm{far}$ as the negative scores, these were expected due to the scoring of the EORTC functional scales, where high values show good functioning of the patient as opposed to the CFS subscales, where high values indicate high levels of fatigue (table 5).

\section{Convergent validity of CFS}

Convergent validity is demonstrated with the correlation between multiple measures that should operate in similar ways. In the current study, the convergent validity of the Greek version of CFS was demonstrated by calculating the Pearson correlation coefficients between the CFS total/subscale scores and the EORTC QLQ-C30 Global Health Status, the association of which with fatigue was previously reported. ${ }^{63} 64$

Convergent validity of CFS indicated that all the correlations of the Global Health Status (q29-q30) were significant. Negative correlations were expected, due to the reverse meaning of the instrument 'global health status', which shows that the higher the CRF levels the lower the global health status levels and vice-versa (table 6).

\section{DISCUSSION}

This study described the translation and psychometric testing in terms of reliability, construct validity, criterion validity and convergent validity of the Greek version of the CFS scale. The internal consistency of the CFS (total scale) was found to be high (0.916) and was higher than the original study $(\alpha=0.88)$. Furthermore, in both validation studies the cognitive subscale had the lowest $\alpha$ coefficients (0.79 and 0.79) and the physical subscale had the highest (0.92 and 0.89 , respectively). In comparison with the original validation study, ${ }^{41}$ the three dimensions of the original fatigue scale appeared to also be present in the Greek version of the scale, with a minor variation change. The good stability of the scale
Table 6 Convergent validity of CFS

\begin{tabular}{lllll}
\hline Scale & CFS & $\begin{array}{l}\text { CFS } \\
\text { physical }\end{array}$ & $\begin{array}{l}\text { CFS } \\
\text { affective }\end{array}$ & $\begin{array}{l}\text { CFS } \\
\text { cognitive }\end{array}$ \\
\hline $\begin{array}{l}\text { Global } \\
\text { health } \\
\text { status/QoL }\end{array}$ & $-0.598^{*}$ & $-0.559^{*}$ & $-0.553^{*}$ & $-0.252^{*}$ \\
\hline *Correlation is significant at the $1 \%$ level. & & \\
\end{tabular}

found in this study $(\mathrm{r}=0.79, \mathrm{p}<0.001)$ was comparable with that of the original study $(\mathrm{r}=0.80, \mathrm{p}<0.001)$. The mean scores in this study were found higher compared with the original across all the three subscales. This finding could possibly be attributed to the patients' advanced stage of the disease, in contrast to the original study where only $26.7 \%$ of the patients were classified as patients with advanced prostate cancer. This is a finding consistent to the relevant literature. ${ }^{6}$ Additionally, the patients in this study were on active chemotherapy treatment for their disease and this could have also contributed to experiencing more severe fatigue, an interpretation that is also supported by the literature. ${ }^{65}$ No information is provided in the original validation study on this aspect of the care. Despite the differences in the mean scores between the current and the original validation study, the findings showed that patients in both studies scored the lowest (indicating lower fatigue levels) in relation to the cognitive elements of fatigue. The current validation study also provided evidence on the criterion validity of the CFS that the original and subsequent validation studies did not provide.

The CFS and EORTC fatigue were positively significantly correlated. The correlations between the CFS physical and EORTC physical subscales were found to be significant as well. The test-retest reliability showed acceptable Pearson correlation coefficients across all the three subscales, a finding which is comparable with that of the original validation study. Overall, the Greek version of the CFS appeared to be a valid and reliable scale in the assessment of CRF in patients with advanced

\begin{tabular}{|c|c|c|c|c|c|c|}
\hline & $\begin{array}{l}\text { CFS } \\
\text { physical }\end{array}$ & $\begin{array}{l}\text { CFS } \\
\text { affective }\end{array}$ & $\begin{array}{l}\text { CFS } \\
\text { cognitive }\end{array}$ & $\begin{array}{l}\text { EORTC physical } \\
\text { function }\end{array}$ & $\begin{array}{l}\text { EORTC cognitive } \\
\text { function }\end{array}$ & $\begin{array}{l}\text { EORTC } \\
\text { fatigue }\end{array}$ \\
\hline CFS & $0.935^{\star}$ & $0.663^{*}$ & $0.726^{\star}$ & $-0.675^{\star}$ & $-0.550^{*}$ & $0.745^{*}$ \\
\hline CFS physical & & $0.449^{*}$ & $0.621^{*}$ & $-0.732^{*}$ & $-0.586^{\star}$ & $0.817^{*}$ \\
\hline CFS affective & & & $0.180 \dagger$ & $-0.328^{\star}$ & -0.153 & $0.345^{*}$ \\
\hline CFS cognitive & & & & $-0.422^{*}$ & $-0.500^{*}$ & $0.469^{*}$ \\
\hline $\begin{array}{l}\text { EORTC physical } \\
\text { function }\end{array}$ & & & & & $0.632^{*}$ & $-0.767^{*}$ \\
\hline $\begin{array}{l}\text { EORTC cognitive } \\
\text { function }\end{array}$ & & & & & & $-0.666^{\star}$ \\
\hline
\end{tabular}

${ }^{*}$ Correlation is significant at the $1 \%$ level.

†Correlation is significant at the $5 \%$ level. 
prostate cancer. This is a major contribution to the literature as it provides evidence of the scale's validity and reliability in a site-specific cancer population. Although the methods in the current study and the preceding validation studies differ to the original validation study, the results showed that the Greek version of the CFS complements with consistency the positive results of the previous validation studies. ${ }^{51-5366}$

Therefore, as in previous validation studies, the sample size was big enough in order to be generalised in the patient population with site-specific cancer. However, previous validation studies have been conducted in patients with various types of cancer and not specifically in prostate cancer. For example, in the study of Kröz et $a \tilde{l}^{1}$ in a sample of 114 patients with cancer, only three patients were diagnosed with prostate cancer and 35 of the overall sample had been metastatic. In the study by Shun $e t a \tilde{l}^{3}$ with a sample of 243 patients, only 20 patients were with prostate cancer. Only in the study of Montazeri et $a \bar{l}^{2}$ was the testing conducted in patient population with site-specific cancer (112 patients with breast cancer in stage II).

Other validation studies were conducted in order to measure CRF in patients with prostate cancer using different scales. ${ }^{67} 68$ In particular, the validation study of Cessna $e t a l^{67}$ used the 7-item Patient-Reported Outcome Measurement Information System Cancer Fatigue Short-Form scale. The study was conducted on 121 men with prostate cancer and 136 patients scheduled to undergo haematopoietic cell transplantation for haematologic cancer. Results indicated a satisfactory internal consistency and reliability in both samples (Cronbach's $\alpha \mathrm{a}=0.86$ ). In addition, fatigue scores were significantly higher in patients with CRF.

Furthermore, Fillion et al ${ }^{68}$ conducted a validation study in order to examine the validity and reliability of the French Canadian adaptation of the Multidimensional Fatigue Inventory (MFI) in 277 patients with breast cancer and 327 patients with prostate cancer undergoing therapy. Confirmatory factor analysis of the four-factor model revealed an acceptable fit $(\mathrm{CFI}=0.909$; $\mathrm{CFI}=0.901 ; \mathrm{NFI}=0.891$; RMSEA=0.084). As for the reliability of the scale, Cronbach's $\alpha$ ranged from 0.68 for the reduced motivation subscale to 0.89 for the general and physical fatigue subscale, whereas the total MFI score ( 15 items), was $\alpha=0.90$, which indicated good reliability. Intercorrelations among subscales indicated a range from 0.39 to 0.64 . As far as the correlations with the total score range from 0.68 to 0.90 , all found to be significant at $\mathrm{a}=0.01$.

\section{CONCLUSION}

This is the first validation study of the CRF Scale in Greek and warrants its use in the assessment of fatigue in patient with advanced prostate cancer. The CFS is useful in evaluating CRF experienced by patients diagnosed with advanced prostate cancer. This finding would allow the identification of patients who are at greatest risk for severe fatigue based on the dose and duration of therapy. Additionally, the determination of predictors of interindividual differences in fatigue trajectories may provide information on the underlying mechanisms for fatigue associated with chemotherapy as well as providing the basis for the development and inception of more effective interventions. The CFS can potentially be valuable to test the effectiveness of interventions used to manage fatigue. Further testing and validation is needed in the early stages of the disease and on patients in later chemotherapy cycles and patients undergoing fatigue-reducing interventions.

Twitter Follow Andreas Charalambous @AndreasC466

Acknowledgements The authors would like to thank all the patients participated in the current study. The authors would also like to thank Miss Samantha Robb for editing the manuscript. The study is supported by the Cyprus University Open Access Author's Fund.

Contributors AC conceived and designed the study, collected analysed the data and approved the final manuscript. CK prepared all the draft versions of the manuscript. MC collected the data and edited and approved the final version of the manuscript. CK edited and approved the final version of the manuscript.

Funding Cyprus University of Technology.

Competing interests None declared.

Ethics approval Cyprus National Bioethics Committee (CNBC 2010/06), Ministry of Health of Cyprus (MH 5.04.019).

Provenance and peer review Not commissioned; externally peer reviewed.

Data sharing statement No additional data are available.

Open Access This is an Open Access article distributed in accordance with the Creative Commons Attribution Non Commercial (CC BY-NC 4.0) license, which permits others to distribute, remix, adapt, build upon this work noncommercially, and license their derivative works on different terms, provided the original work is properly cited and the use is non-commercial. See: http:// creativecommons.org/licenses/by-nc/4.0/

\section{REFERENCES}

1. NCCN Clinical Practice Guidelines in Oncology. http:// oralcancerfoundation.org/treatment/pdf/fatigue.pdf (accessed 17 Feb 2016).

2. Cella D, Peterman A, Passik S, et al. Progress toward guidelines for the management of fatigue. Oncology (Williston Park) 1998;12:369-77.

3. Jacobsen PB. Assessment of fatigue in cancer patients. J Nat Cancer Inst Monogr 2004;2004:93-7.

4. Jean-Pierre $P$, Figueroa-Moseley CD, Kohli S, et al. Assessment of cancer-related fatigue: implications for clinical diagnosis and treatment. Oncologist 2007;12(Suppl 1):11-21.

5. Weis J. Cancer-related fatigue: prevalence, assessment and treatment strategies. Expert Rev Pharmacoecon Outcomes Res 2011;11:441-6.

6. Hofman M, Ryan JL, Figueroa-Moseley CD, et al. Cancer-related fatigue: the scale of the problem. Oncologist 2007;12(Suppl 1):4-10.

7. Goedendorp MM, Gielissen MFM, Verhagen CAH, et al. Severe fatigue and related factors in cancer patients before the initiation of treatment. Br J Cancer 2008;99:1408-14.

8. Forlenza MJ, Hall P, Lichtenstein P, et al. Epidemiology of cancer-related fatigue in the Swedish twin registry. Cancer 2005;104:2022-31.

9. Miaskowski C, Paul SM, Cooper BA, et al. Trajectories of fatigue in men with prostate cancer before, during, and after radiation therapy. J Pain Symptom Manage 2008;35:632-43. 
10. Rodriguez-Vida A, Chowdhury S, Chowdhury S. Management of fatigue and anaemia in men treated with androgen deprivation therapy. Trends Urol Men's Heal 2014;5:25-8.

11. Minton O, Stone P. A systematic review of the scales used for the measurement of cancer-related fatigue (CRF). Ann Oncol 2009;20:17-25.

12. McCorkle R, Quint-Benoliel J. Symptom distress, current concerns and mood disturbance after diagnosis of life-threatening disease. Soc Sci Med 1983;17:431-8.

13. de Haes JC, van Knippenberg FC, Neijt JP. Measuring psychological and physical distress in cancer patients: structure and application of the Rotterdam Symptom Checklist. Br J Cancer 1990;62:1034-8.

14. Degner LF, Sloan JA. Symptom distress in newly diagnosed ambulatory cancer patients and as a predictor of survival in lung cancer. J Pain Symptom Manage 1995;10:423-31.

15. Sarna $L$, Brecht M-L. Dimensions of symptom distress in women with advanced lung cancer: A factor analysis. Hear Lung J Acute Crit Care 1997;26:23-30

16. McCorkle R, Young K. Development of a symptom distress scale. Cancer Nurs 1978;1:373-8.

17. Schneider $\mathrm{L}$. Identification of human concems by cancer patients. In: Kellogg Cl, Sullivan BJ, eds. Current perspectives of oncology nursing. St Louis: C V Mosby, 1978:89-98.

18. Aaronson NK, Ahmedzai S, Bergman B, et al. The European Organisation for Research and Treatment of Cancer QLQ-C30: a quality-of-life instrument for use in international clinical trials in oncology. J Natl Cancer Inst 1993;85:365-76.

19. Knobel H, Loge JH, Brenne E, et al. The validity of EORTC QLQ-C30 fatigue scale in advanced cancer patients and cancer survivors. PalliatMed 2003;17:664-72.

20. Storey DJ, Waters RA, Hibberd CJ, et al. Clinically relevant fatigue in cancer outpatients: The Edinburgh Cancer Centre symptom study. Ann Oncol 2007:18:1861-9.

21. Kyriaki M, Eleni T, Efi P, et al. The EORTC core quality of life questionnaire (QLQ-C30, version 3.0) in terminally ill cancer patients under palliative care: validity and reliability in a Hellenic sample. Int J Cancer 2001;94:135-9.

22. McHorney CA, Ware JE, Raczek AE. The Mos 36-Item Short-Form Health Survey (Sf-36) II. Psychometric and Clinical-Tests of Validity in Measuring Physical and Mental-Health Constructs. Med Care 1993:31:247-63.

23. Pappa E, Kontodimopoulos N, Niakas D. Validating and norming of the Greek SF-36 Health Survey. Qual Life Res 2005:14:1433-8.

24. Cleeland CS, Mendoza TR, Wang XS, et al. Assessing symptom distress in cancer patients: the M.D. Anderson Symptom Inventory. Cancer 2000;89:1634-46.

25. Mystakidou K, Cleeland C, Tsilika E, et al. Greek M.D. Anderson Symptom Inventory: validation and utility in cancer patients. Oncology 2004;67:203-10.

26. Kirsh KL, Passik S, Holtsclaw E, et al. I get tired for no reason: a single item screening for cancer-related fatigue. J Pain Symptom Manage 2001;22:931-7.

27. Rhoten D. Fatigue and the postsurgical patient. In: Norris CM, ed. Concept Clarification in Nursing. Rockville, MD: Aspen Publisher, 1982:277-300.

28. Glaus A. Assessment of fatigue in cancer and non-cancer patients and in healthy individuals. Support Care Cancer 1993;1:305-15.

29. Mendoza TR, Wang XS, Cleeland CS, et al. The rapid assessment of fatigue severity in cancer patients: Use of the brief fatigue inventory. Cancer 1999;85:1186-96

30. Mystakidou K, Tsilika E, Parpa E, et al. Psychometric Properties of the Brief Fatigue Inventory in Greek Patients with Advanced Cancer. $J$ Pain Symptom Manage 2008;36:367-73.

31. Yellen SB, Cella DF, Webster K, et al. Measuring fatigue and other anemia-related symptoms with the Functional Assessment of Cancer Therapy (FACT) measurement system. J Pain Symptom Manage 1997:13:63-74

32. Cella D, Eton DT, Lai JS, et al. Combining Anchor and Distribution-Based Methods to Derive Minimal Clinically Important Differences on the Functional Assessment of Cancer Therapy (FACT) Anemia and Fatigue Scales. J Pain Symptom Manage 2002;24:547-61.

33. McNair DM, Lorr M, Droppleman LF. Profile of mood states manual educational and industrial testing service. CA: San Diego, 1971

34. Norcross JC, Guadagnoli E, Prochaska JO. Factor structure of the Profile of Mood States (POMS): two partial replications. J Clin Psychol 1984;40:1270-7.
35. Meek PM, Nail LM, Barsevick A, et al. Psychometric testing of fatigue instruments for use with cancer patients. Nurs Res 2000;49:181-90.

36. Lee KA, Hicks G, Nino-Murcia G. Validity and reliability of a scale to measure fatigue. Psychiatry Res 1991;36:291-8.

37. Stein KD, Martin SC, Hann DM, et al. A Multidimensional Measure of Fatigue for Use with Cancer Patients. Cancer Pract 1998;6:143-52.

38. Glaus A. Fatigue in patients with cancer. Analysis and assessment. Recent Results Cancer Res 1998;145:I-XI, 1-172.

39. Piper BF, Dibble SL, Dodd MJ, et al. The revised Piper Fatigue Scale: psychometric evaluation in women with breast cancer. Oncol Nurs Forum 1998:25:677-84.

40. Schwartz A, Meek P. Additional construct validity of the Schwartz Cancer Fatigue Scale. J Nurs Meas 1999;7:35-45.

41. Okuyama T, Akechi T, Kugaya A, et al. Development and Validation of the Cancer Fatigue Scale. J Pain Symptom Manage 2000;19:5-14.

42. Hann DM, Jacobsen PB, Azzarello LM, et al. Measurement of fatigue in cancer patients: development and validation of the fatigue symptom inventory. Qual Life Res 1998;7:301-10.

43. Hann DM, Denniston MM, Baker F. Measurement of fatigue in cancer patients: further validation of the Fatigue Symptom Inventory. Qual Life Res 2000;9:847-54.

44. Chalder T, Berelowitz G, Pawlikowska T, et al. Development of a fatigue scale. J Psychosom Res 1993;37:147-53.

45. Berger AM. Patterns of fatigue and activity and rest during adjuvant breast cancer chemotherapy. Oncol Nurs Forum 1998;25:51-62

46. Berger $A M$, Farr $L$. The influence of daytime inactivity and nighttime restlessness on cancer-related fatigue. Oncol Nurs Forum 1999;26:1663-71.

47. Berger AM, Higginbotham P. Correlates of fatigue during and following adjuvant breast cancer chemotherapy: a pilot study. Oncol Nurs Forum 2000;27:1443-8.

48. Can G, Durna Z, Aydiner A. Assessment of fatigue in and care needs of Turkish women with breast cancer. Cancer Nurs 2004;27:153-61.

49. Gaston-Johansson F, Fall-Dickson JM, Bakos AB, et al. Fatigue, pain, and depression in pre-autotransplant breast cancer patients. Cancer Pract 1999;7:240-7.

50. Mills PJ, Parker B, Dimsdale JE, et al. The relationship between fatigue and quality of life and inflammation during anthracycline-based chemotherapy in breast cancer. Biol Psychol 2005;69:85-96.

51. Kröz M, Zerm R, Reif M, et al. Validation of the German version of the Cancer Fatigue Scale (CFS-D). Eur J Cancer Care (Engl) 2008;17:33-41.

52. Montazeri A, Haghighat S, Ebrahimi M. P-297/1099/The Cancer Fatigue Scale (CFS): translation and Validation Study of the Iranian Version. Qual Life Res 2005;14:2132.

53. Shun SC, Beck SL, Pett MA, et al. Psychometric Testing of Three Chinese Fatigue Instruments in Taiwan. J Pain Symptom Manage 2006;32:155-67.

54. World Medical Association. World Medical Association Declaration of Helsinki: ethical principles for medical research involving human subjects. JAMA 2013;310:2191-4.

55. Beaton DE, Bombardier C, Guillemin F, et al. Guidelines for the process of cross-cultural adaptation of self-report measures. Spine (Phila Pa 1976) 2000;25:3186-91.

56. Ziliak ST, McCloskey DN. The cult of statistical significance : how the standard error costs us jobs, justice, and lives. 1st edn. Ann Arbor, Michigan: University of Michigan Press, 2008.

57. Charalambous A, Kouta C. Cancer Related Fatigue and Quality of Life in Patients with Advanced Prostate Cancer Undergoing Chemotherapy. Biomed Res Int 2016;2016:3989286.

58. Cerny BA, Kaiser HF. A study of a measure of sampling adequacy for factor-analytic correlation matrices. Multivariate Behav Res 2010;12:43-7.

59. Dziuban CD, Shirkey EC. When is a correlation matrix appropriate for factor analysis? Some decision rules. Psychol Bull 1974;81:358-61.

60. Kaiser HF. A second generation little jiffy. Psychometrika 1970;35:401-15.

61. Bartlett MS. Properties of Sufficiency and Statistical Tests. Proc $R$ Soc A Math Phys Eng Sci 1937;160:268-82.

62. Suhr DD. Paper 203-30 Principal Component Analysis vs. Exploratory Factor Analysis. http://www2.sas.com/proceedings/ sugi30/203-30.pdf (accessed 22 Jul 2016). 
63. Ferrell BR, Grant M, Dean GE, et al. 'Bone tired': the experience of fatigue and its impact on quality of life. Oncol Nurs Forum 1996;23:1539-47.

64. Okuyama T, Wang XS, Akechi T, et al. Validation Study of the Japanese Version of the Brief Fatigue Inventory. J Pain Symptom Manage 2003;25:106-17.

65. van Andel G, Fernandez de Moral P, Caris CTM, et al. A randomized study comparing epirubicin in a 4-weekly versus a weekly intravenous regimen in patients with metastatic, hormone resistant, prostatic carcinoma: effects on health related quality of life. World J Urol 2003;21:177-82.
66. Okuyama T, Wang $\mathrm{X}$, Akechi T. Japanese version of the MD Anderson Symptom Inventory: a validation study. J Pain Symptom Manag 2003;26:1093-104.

67. Cessna JM, Jim HSL, Sutton SK, et al. Evaluation of the psychometric properties of the PROMIS Cancer Fatigue Short Form with cancer patients. J Psychosom Res 2016;81:9-13.

68. Fillion L, Gélinas C, Simard S, et al. Validation Evidence for the French Canadian Adaptation of the Multidimensional Fatigue Inventory as a Measure of Cancer-related Fatigue. Cancer Nurs 2003;26:143-54. 